\title{
Analysis of eye-tracking behaviours in a pediatric trauma simulation
}

\author{
Omar Damji, BHSc, MSc, MD* ${ }^{\dagger \ddagger}$; Patricia Lee-Nobbee, MD, FRCPC ${ }^{\dagger}$; David Borkenhagen, BSc, \\ $\mathrm{MSc}^{* \S}$; Adam Cheng, MD, FRCPC ${ }^{\dagger \ddagger}$
}

\section{ABSTRACT}

Eye-tracking devices are able to capture eye movements, which are further characterized by fixations. The application of eye tracking in a trauma setting has not been explored. Visual fixation can be utilized as a surrogate measure of attention during the management of a trauma patient. We aimed to determine the feasibility of using eye tracking and to characterize eye tracking behaviours of pediatric emergency medicine physicians during management of a simulated pediatric trauma patient. Each participant was equipped with a headmounted eye-tracking device during a standardized simulated pediatric trauma scenario. Each session was video recorded, with visual fixations defined as $>0.2$ seconds, and characterized by start time, duration, and the area of interest. Data from seven videos were analysed; $35 \%$ of eye fixations were directed towards the mannequin, $16 \%$ towards the monitor, and $13 \%$ towards the bedside doctor. Visual eye tracking in a trauma simulation is feasible. Frequency of fixations tends to be highest towards the patient. Eye tracking within trauma simulation may provide new insights into quality improvement and inform advancements in pediatric trauma.

\section{RÉSUMÉ}

Les dispositifs de monitorage oculaire, ou oculomètres, peuvent détecter les mouvements des yeux, phénomène qui se caractérise aussi par des fixations. L'application du monitorage oculaire dans les contextes de trauma n'a pas encore été étudiée. Par ailleurs, les fixations visuelles peuvent servir de mesures de substitution de l'attention pendant le traitement des patients ayant subi un trauma. Aussi l'étude visait-elle à déterminer la faisabilité de l'utilisation du monitorage oculaire et à caractériser, à l'aide de celui-ci, le comportement des médecins en pédiatrie d'urgence durant la prise en charge d'une simulation de trauma chez un enfant. Chaque participant portait un oculomètre sur la tête et faisait l'objet de suivi durant une simulation uniformisée de prise en charge d'un cas de trauma chez un enfant. Chaque séance a été enregistrée par vidéo, et les fixations visuelles, définies comme des pauses d'une durée $>0,2 \mathrm{~s}$, ont été caractérisées par le début et la durée ainsi que le champ d'intérêt. Ont été analysées des données de 7 vidéos; $35 \%$ des fixations visuelles étaient dirigées vers le mannequin; $16 \%$, vers le moniteur et $13 \%$, vers le médecin traitant. Le monitorage oculaire dans les simulations de trauma s'avère donc possible. C'est sur le patient que les fixations visuelles tendent le plus à se porter. Le monitorage oculaire dans les simulations de trauma pourrait jeter un éclairage nouveau sur l'amélioration de la qualité et guider des changements dans la prise en charge des traumas chez les enfants.
Keywords: eye tracking, gaze preference, pediatric trauma, simulation, situational awareness

\section{BACKGROUND}

By mapping movements of the eye in various clinical settings, eye tracking can be used as a tool to characterize the visual fixation of healthcare providers. ${ }^{1,2}$ Characterization of visual fixation in various clinical environments helps build on our understanding of behaviours that promote best practices. ${ }^{1}$ Although eye tracking has been used in various clinical settings, it has not been applied to pediatric trauma resuscitation. In this study, we used simulation as a tool to study eye tracking behaviours in pediatric trauma resuscitation.

Each year, thousands of children are hospitalized due to trauma-related incidents. ${ }^{3}$ The burden of pediatric trauma can be lessened with effective and efficient emergency care. ${ }^{3}$ Effective management requires multiple healthcare providers working together with a shared understanding of goals for patient care. To achieve this, situational awareness is key. ${ }^{4}$ Situational awareness is the ability of an individual to process information about her or his environment. ${ }^{4}$ This concept consists of three levels: Level 1 - acquisition of relevant information; Level 2 - integration of information leading to understanding; and Level 3 - prediction of future states. ${ }^{4}$ Eye-tracking technology permits the collection of data regarding Level 1 of situational awareness via a video analysis. Eye-tracking data collected during pediatric trauma may build our understanding of situational awareness amongst trauma team members, which can be used to guide the development of future educational interventions. ${ }^{4-6}$

From the *University of Calgary Cumming School of Medicine, Calgary, AB; †Department of Emergency Medicine, University of Calgary, Calgary, $A B$; $¥$ Alberta Children's Hospital Research Institute (ACHRI), Calgary, AB; and §Ward of the 21st Century (W21C) Research and Innovation Centre, University of Calgary, Calgary, AB.

Correspondence to: Dr. Omar Damji, PGY2 Emergency Medicine (2022 Candidate), University of Calgary Cumming School of Medicine, Department of Emergency Medicine, 2888 Shaganappi Trail NW, Calgary, AB T3B 6A8; Email: odamji@ucalgary.ca 


\section{PURPOSE}

We sought to determine the feasibility of using eye tracking in pediatric trauma simulation and to characterize the eye-tracking behaviours amongst physicians during the management of a simulated pediatric trauma patient. We hypothesized that eye-tracking technology is feasible and visual fixation would be focused on the patient.

\section{DESCRIPTION OF INNOVATION}

\section{Methods}

This study was an observational, non-blinded, simulation-based study. Research ethics board approval was obtained from The University of Calgary Behavioural Research Ethics Board. Nine pediatric emergency medicine (PEM) physicians (years in practice: 1 to 15 years) were recruited to participate as a trauma team leader (TTL) in a simulated pediatric trauma scenario (blunt trauma with hypovolemic shock) with nurses, respiratory therapists, paramedics, and a bedside doctor filling out the roles of the other trauma team members. TTLs were fitted with a head-mounted Mobile Eye $\mathrm{XG}^{\mathrm{TM}}$ eye-tracking device. All sessions were video recorded through the eye camera and scene camera. As means of standardization, the first 5 minutes ${ }^{7}$ of each session were manually analysed by watching the video using Noldus Observe $\mathrm{XT}^{\mathrm{TM}}$ software. A coding matrix was used to identify and mark areas of interest (AOIs), or instances where the visual gaze remained fixated on a specific area for $>0.2$ seconds. For each fixation, the start time of fixation, duration, and end-time of fixation were documented. Pre-defined AOIs were identified a priori by consensus via discussion amongst research team, and included the patient, bedside doctor, paramedic, monitor, recording nurse, medication nurse, procedure nurse, fluids, oxygen, checklist, and respiratory therapist.

\section{RESULTS}

Nine video sessions were recorded, seven analysed, and two excluded due to loss of calibration mid-simulation. While cumbersome at times, eye-tracking devices were well tolerated by participants and did not impede their ability to make decisions or perform tasks as a TTL; $35 \%$ of eye fixations were directed towards the

\begin{tabular}{|c|c|c|c|c|}
\hline & $\begin{array}{c}\text { Average } \\
\text { number of } \\
\text { fixations (n) }\end{array}$ & $\begin{array}{c}\text { Average } \\
\text { total time of } \\
\text { fixations (s) }\end{array}$ & $\begin{array}{l}\text { Average } \\
\text { fixation } \\
\text { time (s) }\end{array}$ & $\begin{array}{c}\text { Average } \\
\text { proportion of } \\
\text { fixation time } \\
(\%)\end{array}$ \\
\hline Patient & 43 & 74.71 & 0.90 & 34.99 \\
\hline $\begin{array}{r}\text { Bedside } \\
\text { doctor }\end{array}$ & 26 & 26.59 & 0.50 & 12.97 \\
\hline $\begin{array}{l}\text { Medication } \\
\text { nurse }\end{array}$ & 10 & 10.90 & 0.49 & 5.15 \\
\hline $\begin{array}{l}\text { Procedure } \\
\text { nurse }\end{array}$ & 9 & 13.87 & 0.86 & 6.60 \\
\hline $\begin{array}{l}\text { Recording } \\
\text { nurse }\end{array}$ & 2 & 2.06 & 0.48 & 0.99 \\
\hline $\mathrm{RT}$ & 19 & 19.85 & 0.51 & 9.39 \\
\hline EMT & 3 & 10.71 & 3.51 & 6.13 \\
\hline Monitor & 26 & 34.93 & 0.58 & 16.14 \\
\hline Medications & 2 & 1.78 & 0.40 & 0.85 \\
\hline Fluids & 5 & 4.90 & 0.41 & 2.29 \\
\hline Oxygen & 5 & 3.86 & 0.33 & 1.89 \\
\hline Checklist & 4 & 5.33 & 0.57 & 2.60 \\
\hline
\end{tabular}

mannequin, $16 \%$ towards the monitor, and $13 \%$ towards the bedside doctor (Table 1 and Figure 1).

\section{DISCUSSION}

Our study suggests that use of eye tracking for simulated pediatric trauma is feasible, and that TTLs primarily fixate on the patient during resuscitation. Exploring patterns of visual fixation amongst TTLs shed light on one key element of situational awareness (i.e., Level 1), verifying that amongst PEM physicians, patient assessment serves as a key source of information during trauma. The AOIs that we studied include both "human" (i.e., including simulated patient) and nonhuman elements. Social norms dictate some degree of visual fixation when another human being is speaking compared to the observation of a piece of equipment. Likewise, a patient who is speaking may get even more fixation than one who is obtunded. These social norms are balanced against the importance of data/information offered by objects in the clinical environment - all variables that likely contributed to patterns of visual fixation amongst TTLs.

Our study adds to existing knowledge of the application of eye tracking in medical education, but is the first of its 


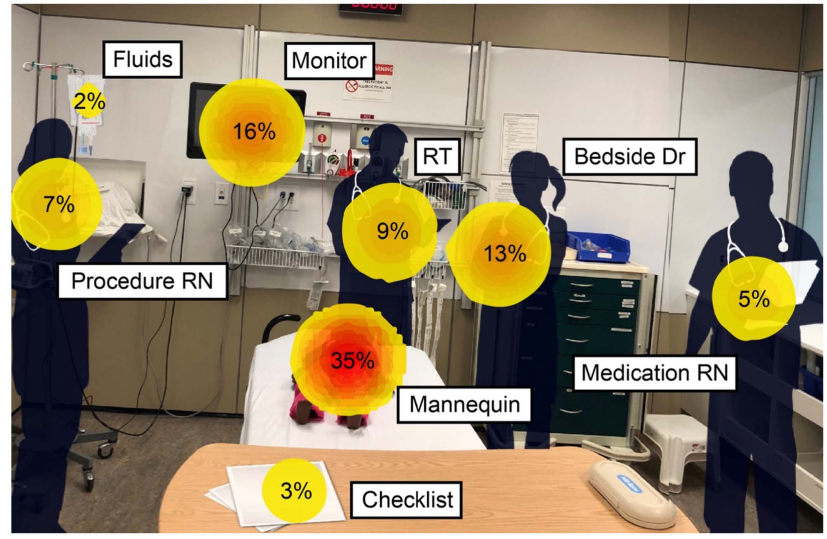

Figure 1. Heat map representing gaze preference towards pre-defined AOls from most commonly viewed to least commonly viewed. This is depicted by the percentage, size of circle as well as colour. A darker core within the circle relates to an increased proportion of fixations during the simulation. $\mathrm{RT}=$ respiratory therapist; $\mathrm{RN}=$ registered nurse; $\mathrm{Dr}=$ doctor.

kind in pediatric trauma. ${ }^{5-7}$ In neonatal resuscitation, gaze preference amongst six expert consultants was focused primarily towards the monitor rather than the neonate. ${ }^{8}$ In a simulated pediatric intensive care unit (PICU) environment, expert consultants focused their gaze predominantly on the chest and airway of the patient, whereas novice clinicians had visual preference directed towards the defibrillator. ${ }^{9}$ Both studies elucidate an important difference in visual fixation during resuscitation, with the PICU study indicating a role for eye tracking in characterizing expert behaviours.

The small size and descriptive nature of this study is a limitation. Because this was a simulation-based study, we cannot confirm whether our results are generalizable to the real clinical environment. Our study was not designed to determine whether focusing visual fixation on the patient leads to a more effective resuscitation. Mis-calibration (movement of the camera off of its pivot) of the eyetracking unit was a challenge and resulted in two videos being removed from analysis. We don't foresee this as a feasibility issue moving forward because new eye-tracking devices have improved calibration functionality. Apart from this, no other technical malfunctions were encountered with the eye-tracking units. Some participants reported the unit as being cumbersome at times, but all felt that this did not subjectively affect their ability to lead the resuscitation. In fact, most participants described not noticing the eyetracking device after only a couple of minutes.
Our study provides data supporting the use and feasibility of eye tracking in pediatric trauma. In the future, we hope to compare and contrast eye-tracking behaviours in trainees versus attending physicians. ${ }^{7}$ Assuming that experts have a better sense of what is important to focus on, contrasting this to trainee's visual fixation may identify opportunities for behaviour change. ${ }^{10}$ Secondly, we hope to study visual eye tracking in other high-stakes clinical contexts (e.g., cardiac arrest) and during technical skills (e.g., intubation). We believe that the use of eye technology can enhance our understanding of situational awareness in various clinical contexts, thus providing a source of data to inform positive change in clinical practice.

Competing interests: None declared.

\section{REFERENCES}

1. Blondon K, Wipfli R, Lovis C. Use of eye-tracking technology in clinical reasoning: a systematic review. Stud Health Technol Inform 2015;210:90-4.

2. Goldberg JH, Kotval XP. Computer interface evaluation using eye movements: methods and constructs. Int 7 Ind Ergon 1999;24(6):631-45.

3. Pike I, Khalil M, Yanchar NL, et al. Establishing an injury indicator for severe paediatric injury. Inj Prev 2017;23 (2):118-23.

4. Endsley MR. Sage Fournals. Human Factors. Toward a theory of situation awareness in dynamic systems; 1995, 32-64. Available at: https://doi.org/10.1518\%2F001872095779049543 (accessed November 8, 2017).

5. Ashraf H, Sodergren $M H$, Merali N, et al. Eye-tracking technology in medical education: a systematic review. Med Teach 2018;40(1):62-9.

6. Henneman EA, Marquard JL, Fisher DL, Gawlinski A. Eye tracking: a novel approach for evaluating and improving the safety of healthcare processes in the simulated setting. Simul Healthc 2017;12(1):51-6.

7. White MR, Braund H, Howes D, et al. Getting inside the expert's head: an analysis of physician cognitive processes during trauma resuscitations. Ann Emerg Med 2018;72(3):289-98.

8. Law BHY, Cheung P-Y, Wagner M, et al. Analysis of neonatal resuscitation using eye tracking: a pilot study. Arch Dis Child 2018;103(1):F82-4.

9. McNaughten B, Hart C, Gallagher S, et al. Clinician's gaze behaviour in simulated paediatric emergencies. Arch Dis Child 2018. Available at: http://adc.bmj.com/lookup/doi/10. 1136/archdischild-2017-314119. Epub ahead of print.

10. Henneman EA, Cunningham H, Fisher DL, et al. Eye tracking as a debriefing mechanism in the simulated setting improves patient safety practices. 2014;33(3):129-35. 